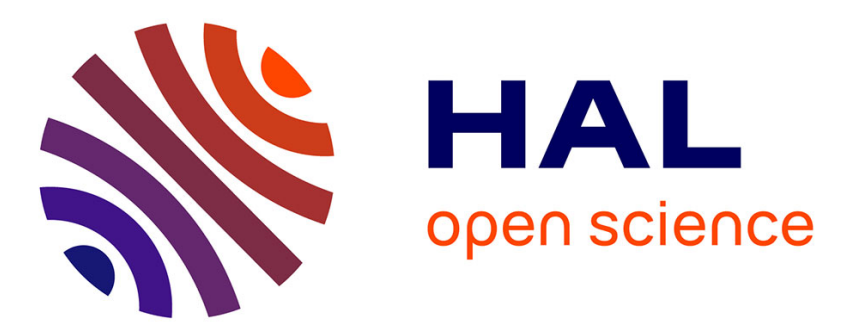

\title{
Absorption and scattering in photo-thermo-refractive glass induced by UV exposure and thermal development
}

\author{
J. Lumeau, L. Glebova, L.B. Glebov
}

\section{To cite this version:}

J. Lumeau, L. Glebova, L.B. Glebov. Absorption and scattering in photo-thermo-refractive glass induced by UV exposure and thermal development. Optical Materials, 2014, 36, pp.621-627. hal00947686

\section{HAL Id: hal-00947686 \\ https://hal.science/hal-00947686}

Submitted on 13 Mar 2019

HAL is a multi-disciplinary open access archive for the deposit and dissemination of scientific research documents, whether they are published or not. The documents may come from teaching and research institutions in France or abroad, or from public or private research centers.
L'archive ouverte pluridisciplinaire HAL, est destinée au dépôt et à la diffusion de documents scientifiques de niveau recherche, publiés ou non, émanant des établissements d'enseignement et de recherche français ou étrangers, des laboratoires publics ou privés. 


\section{Elsevier Editorial System(tm) for Optical Materials Manuscript Draft}

Manuscript Number: OM-D-13-00833R2

Title: Absorption and scattering in photo-thermo-refractive glass induced by UV exposure and thermal development

Article Type: Original Research

Keywords: Absorption; Scattering; Nano-particles; Photosensitive Glass

Corresponding Author: Dr. Julien Lumeau, PhD

Corresponding Author's Institution: CNRS

First Author: Julien Lumeau, PhD

Order of Authors: Julien Lumeau, PhD; Larissa Glebova; Leonid B Glebov

Abstract: Photo-thermo-refractive (PTR) glass is a multicomponent photosensitive silicate glass that, after successive UV-exposure and thermal treatment, exhibits a refractive index change that results from the precipitation of nano-crystalline $\mathrm{NaF}$. This glass is successfully used for the fabrication of holographic optical elements (volume Bragg gratings) that dramatically enhance properties of numerous laser systems and spectrometers. In this paper, induced absorption and scattering that determine efficiency of such elements were studied. It is found that the main contribution to induced absorption is produced by several types of silver containing particles having absorption bands with maxima in the blue-green region with exponential tails extending to the near IR spectral region. Evolution of all absorption bands was studied for different conditions of UV exposure and thermal development. Complex mechanisms of interconversion of silver containing particles is demonstrated as well as the fact that some of these particles can be associated with catalyzers of the nucleation process. It is also found that induced scattering obeys the classic Rayleigh law with an intensity depending on the conditions of UV exposure and thermal development. For short development times, scattering increases with dosage because of increased volume fraction of crystalline phase. For long development times, scattering decreases with dosage because of decreased size of individual crystals. 


\title{
Answers to Editors queries
}

We want to thank you the editor and reviewers for their time spent in analyzing the paper. Below are the answers to the reviewer 2 .

Reviewer \#2: Revised manuscript does a nice job of cleaning up the language as suggested previously. The only exception is the abstract, in which a spelling error remains: "forth power", as opposed to the correct "fourth power". It is OK with this reviewer if the earlier suggested corrections for the abstract not be exactly followed, but I'm assuming the authors would prefer not to have such a glaring error in the abstract.

Finally, I note that the abstract remains not particularly informative, with the final sentence remaining: "Dependence of scattering on conditions of UV exposure and thermal development is studied." I would rather the authors replace that one sentence with two new sentences that concisely state what the other key findings were. But this point I leave to the editor to decide.

We want to apologize for missing some of the last few comments from the reviewer within the abstract. We have included his comments as well as have added some more details to make the abstract more complete. Below is a copy of the abstract showing the main modifications in red.

\begin{abstract}
:
Photo-thermo-refractive (PTR) glass is a multicomponent photosensitive silicate glass that, after successive UV-exposure and thermal treatment, exhibits a refractive index change that results from the precipitation of nano-crystalline $\mathrm{NaF}$. This glass is successfully used for the fabrication of holographic optical elements (volume Bragg gratings) that dramatically enhance properties of numerous laser systems and spectrometers. In this paper, induced absorption and scattering that determine efficiency of such elements were studied. It is found that the main contribution to induced absorption is produced by several types of silver containing particles having absorption bands with maxima in the blue-green region with exponential tails extending to the near IR spectral region. Evolution of all absorption bands was studied for different conditions of UV exposure and thermal development. Complex mechanisms of interconversion of silver containing particles is demonstrated as well as the fact that some of these particles can be associated with catalyzers of the nucleation process. It is also found that induced scattering obeys the classic Rayleigh law with an intensity depending on the conditions of UV exposure and thermal development. For short development times, scattering increases with dosage because of increased volume fraction of crystalline phase. For long development times, scattering decreases with dosage because of decreased size of individual crystals.
\end{abstract}


- Induced absorption and scattering in PTR glass are studied.

- Induced absorption is produced by several types of silver containing particles.

- Structure of the induced absorption depends on thermal development schedule.

- Scattering obeys Rayleigh exponential formula with forth power.

- Dependence of scattering on processing procedure is explained. 


\title{
Absorption and scattering in photo-thermo-refractive glass induced by UV exposure and thermal development
}

\author{
Julien Lumeau $^{1,2}$, Larissa Glebova ${ }^{3}$, Leonid Glebov ${ }^{1}$ \\ ${ }^{1}$ CREOL / the College of Optics and Photonics \\ University of Central Florida \\ 4000, Central Florida Blvd \\ Orlando, FL 32816-2700, USA \\ ${ }^{2}$ Aix-Marseille Université, CNRS, Centrale Marseille, Institut Fresnel, UMR 7249, \\ 13013 Marseille, France \\ ${ }^{3}$ OptiGrate Corporation \\ 562 S, Econ Circle \\ Oviedo, FL 32765 \\ julien.lumeau@fresnel.fr
}

\begin{abstract}
Photo-thermo-refractive (PTR) glass is a multicomponent photosensitive silicate glass that, after successive UV-exposure and thermal treatment, exhibits a refractive index change that results from the precipitation of nano-crystalline NaF. This glass is successfully used for the fabrication of holographic optical elements (volume Bragg gratings) that dramatically enhance properties of numerous laser systems and spectrometers. In this paper, induced absorption and scattering that determine efficiency of such elements were studied. It is found that the main contribution to induced absorption is produced by several types of silver containing particles
\end{abstract}


having absorption bands with maxima in the blue-green region with exponential tails extending to the near IR spectral region. Evolution of all absorption bands was studied for different conditions of UV exposure and thermal development. Complex mechanisms of interconversion of silver containing particles is demonstrated as well as the fact that some of these particles can be associated with catalyzers of the nucleation process. It is also found that induced scattering obeys the classic Rayleigh law with an intensity depending on the conditions of UV exposure and thermal development. For short development times, scattering increases with dosage because of increased volume fraction of crystalline phase. For long development times, scattering decreases with dosage because of decreased size of individual crystals.

Keywords: Absorption; Scattering; Nano-particles; Photosensitive Glass

PACS codes: 78.20.Ci, 78.40.q, 78.35.c, 81.10.h, 81.10.Aj 


\section{Introduction}

Photo-thermo-refractive (PTR) glass is a photosensitive $\mathrm{Na}_{2} \mathrm{O}-\mathrm{NaF}-\mathrm{K}_{2} \mathrm{O}-\mathrm{KBr}-\mathrm{ZnO}-\mathrm{Al}_{2} \mathrm{O}_{3}-\mathrm{SiO}_{2}$ glass, doped with minor amounts of $\mathrm{Ce}, \mathrm{Ag}, \mathrm{Sb}$, and $\mathrm{Sn}$, that undergoes a permanent refractive index change after UV-exposure followed by thermal treatment [1-2]. PTR glass has been used for holographic recording of various types of volume diffractive optical elements [3], and finds a wide range of applications such as spectral beam combining, the selection of transverse and longitudinal modes in laser resonators, beam deflectors, splitters and attenuators [4-5]. A simplified description of the photo-induced reactions in glasses with similar composition can be summarized as:

(i) photoionization of $\mathrm{Ce}^{3+}$ and formation of atomic silver during exposure to $\mathrm{UV}\left(\mathrm{Ag}^{+}+\mathrm{Ce}^{3+}+\mathrm{h} v \rightarrow \mathrm{Ag}^{0}+\mathrm{Ce}^{4+}\right)$

(ii) silver containing particles clustering during an initial stage of thermal treatment below $500^{\circ} \mathrm{C}\left(\mathrm{nAg}^{0}+\mathrm{kT} \rightarrow \mathrm{Ag}^{0}{ }_{n}\right)$, and

(iii) heterogeneous nucleation and growth of $\mathrm{NaF}$ nanocrystals on further heating at temperatures exceeding $500^{\circ} \mathrm{C}[6]$.

It was shown that the refractive index change required for holographic recording is the result of the precipitation of this crystalline phase $[7,8]$. No other crystalline phases were detected in PTR glass developed at relatively low temperatures normally used for hologram recording [9]. In addition, crystalline $\mathrm{NaF}$ does not have any absorption bands in the near-UV, visible and near IR spectral regions. However, it was demonstrated that an induced absorption band mainly in the blue region and with a complex spectrum evolves in the process of thermal treatment of UVexposed samples [10]. It was proposed that this band could be associated with silver and bromine-containing particles. However, no further analysis was carried out at that time. In this 
paper, loss spectra induced in PTR glass after UV-exposure and thermal treatment are analyzed in detail. Photo-induced absorption and scattering were discriminated and then analyzed. Absorption spectra were decomposed into Gaussian functions that could be associated with different types of particles appearing in the glass at different stages of the thermal treatment. Using this model, the evolution of each particle during the nucleation and the thermal development processes were studied. Scattering spectra are also mathematically analyzed and their evolution was also studied at different stages of the thermal treatment.

\section{Experimental}

\subsection{PTR glass preparation}

Samples of a photosensitive PTR glass containing $15 \mathrm{Na}_{2} \mathrm{O}-5 \mathrm{ZnO}-4 \mathrm{Al}_{2} \mathrm{O}_{3}-70 \mathrm{SiO}_{2}-5 \mathrm{NaF}-$ $1 \mathrm{KBr}-0.01 \mathrm{Ag}_{2} \mathrm{O}-0.01 \mathrm{CeO}_{2}(\mathrm{~mol} . \%)$ and minor amounts of $\mathrm{Sn}$ and $\mathrm{Sb}$ were used in this work as in previous studies $[7,11-13]$. The glasses were melted in a platinum crucible, stirred, cooled to the glass transition temperature, and annealed $\left(2\right.$ hours at $460^{\circ} \mathrm{C}$ and cooled down with rate of $0.1 \% \mathrm{~min}$ ). Polished $25 \times 25 \times 5 \mathrm{~mm}^{3}$ samples were prepared from the billet. The homogeneity of the PTR glass samples is a critical parameter affecting crystallization properties [14]. Therefore, optical homogeneity of each sample was tested by the shadow method in a divergent beam of a He-Ne laser and quantified by measurements using a Fizeau interferometer (GPI, Zygo Corp.). The samples prepared for this study had refractive index fluctuations of less than $40 \mathrm{ppm}\left(4 \times 10^{-}\right.$

${ }^{5}$ ), peak-to-valley, across the $25 \times 25 \mathrm{~mm}^{2}$ aperture. 


\subsection{UV-exposure and heat-treatments}

UV-exposure of samples was performed using the beam of a He-Cd laser (power: $4 \mathrm{~mW}$, wavelength: $325 \mathrm{~nm}$, diameter: $1 \mathrm{~mm}$ ). Samples were homogeneously exposed with a dosage ranging from 0.25 to $8 \mathrm{~J} / \mathrm{cm}^{2}$ by scanning the laser beam to produce multiple overlapped stripes on the sample. Dosage was controlled by changing the scanning speed [15]. The samples were heat-treated at 480 and $515^{\circ} \mathrm{C}$. The samples heat-treated at $480^{\circ} \mathrm{C}$ were dropped inside the temperature stabilized furnace and, at the end of each thermal treatment, were quenched in order to control the thermal treatment duration with precision better than 1 minute. This method allowed performing short thermal treatments. The samples treated at $515^{\circ} \mathrm{C}$ were heated from room temperature at a rate about $20 \mathrm{~K} / \mathrm{min}$, aged at $515^{\circ} \mathrm{C}$ and then cooled down to room temperature in the furnace following its natural cooling rate about $2.5 \mathrm{~K} / \mathrm{min}$. Finally, in order to remove any incipient crystallization on surfaces, each sample was ground and re-polished to a flatness better than $\lambda / 2$ at $633 \mathrm{~nm}$.

\subsection{Spectral measurements}

Spectra of losses (sum of absorption and scattering) were measured using a Perkin Elmer Lambda 950 spectrophotometer in the range from 200 to $1700 \mathrm{~nm}$. Optical density $O D=\log _{10}(1 / T)$, where $T$ is transmission, was used for all calculations. Internal optical density $\left(O D_{i}\right)$ was routinely calculated by subtraction of Fresnel reflection $\left(O D_{r}\right)$ that was determined from a dispersion curve of PTR glass: $O D_{i}=O D-O D_{r}$. Losses coefficient was calculated as $L, \mathrm{~cm}^{-1}=A+S=O D_{i} / t$, where A and $\mathrm{S}$ are coefficients of absorption and scattering and $\mathrm{t}$ is the sample's thickness in centimeters. Photometric absolute accuracy of the Perkin Elmer Lambda 950 was about $\Delta \mathrm{OD}= \pm 0.005$ and fluctuations of Fresnel reflection related to the specific 
condition of the surfaces could attain $\Delta \mathrm{OD}_{\mathrm{r}}= \pm 0.005$ resulting in the absolute precision of our spectrophotometric measurement for $0.5-\mathrm{cm}$-thick samples of about $2 \times 10^{-2} \mathrm{~cm}^{-1}$. To achieve higher precision of measurements, both the transmission and the reflection at $1085 \mathrm{~nm}$ were carried out by a precise photometer based on an Yb-doped fiber laser. With this photometer, absolute accuracy of reflection and transmission measurements was about $\pm 0.1 \%$ and, therefore, losses were calculated with precision of $10^{-3} \mathrm{~cm}^{-1}$. Spectra measured using Perkin Elmer Lambda 950 were stitched to the precise photometric data at $1085 \mathrm{~nm}$. Using this technique, the absolute precision of the whole spectrum was improved to $10^{-3} \mathrm{~cm}^{-1}$.

\subsection{Measurements of induced absorption and scattering}

The thermal development process of UV-exposed PTR glass relies on the appearance of silver containing particles that participate in the nucleation process followed by the growth of sodium fluoride crystals which cause the appearance of a permanent refractive index change $[7,8]$. It is well-known that the appearance of silver colloidal particles induces a plasmon resonance that results in an induced absorption band whose position and width depend on their composition and diameter. In Ref. [16], it was shown that depending on the size distribution and on the presence of halides (bromine or chlorine for example), the position of the induced absorption band may vary from 400 to $600 \mathrm{~nm}$. Typical losses spectrum of UV-exposed $\left(4 \mathrm{~J} / \mathrm{cm}^{2}\right.$ at $\left.325 \mathrm{~nm}\right)$ and thermally developed ( 1 hour at $515^{\circ} \mathrm{C}$ ) PTR glass in the range from 300 to $1500 \mathrm{~nm}$ is shown in Fig. 1. Several sources contribute to the losses of UV exposed and thermally developed PTR glass. In UV region, there is the superposition of the absorption of the original glass, mainly a combination of $\mathrm{Ce}^{3+}$ and $\mathrm{Ce}^{4+}$ absorption bands [17], the induced absorption of silver containing particles and color centers [10], and scattering. In the visible and mid-IR ranges, the main 
contributions are from induced absorption of silver containing particles and scattering. Multiple, overlapped induced absorption bands combined with scattering complicate the analysis of such spectra. However, it was shown $[18,19]$, that induced absorption of silver containing particles can be completely bleached by the second harmonic of a Nd:YAG laser at $532 \mathrm{~nm}$. Therefore, using this technique it is possible to extract the induced absorption spectrum by subtracting the losses spectra before and after this optical bleaching. Figure 2 shows the typical induced absorption spectrum of UV exposed and thermally developed PTR glass. One can see that this spectrum has a maximum near $465 \mathrm{~nm}\left(22000 \mathrm{~cm}^{-1}\right)$ and extends from 300 to $1500 \mathrm{~nm}$.

It was found that additional scattering in PTR glass could not be detected after UV-exposure and after nucleation at low temperatures but it appears only after thermal development when a crystalline phase of $\mathrm{NaF}$ precipitated. To extract the spectral dependence of scattering, the absorption spectrum of virgin PTR glass was subtracted from a loss spectrum of the same PTR glass sample that underwent UV exposure, thermal development and optical bleaching described in the previous paragraph. This spectrum is shown in Fig. 3. It includes scattering and changes of absorption that could not be bleached, e.g. absorption of different forms of cerium resulted from its photoionization. It will be shown later that the contribution of absorption in this spectrum is negligible in all parts except the narrow region close to $300 \mathrm{~nm}$. 


\section{Results}

\subsection{Analysis of the induced absorption in PTR glass}

\subsubsection{Gaussian decomposition of induced absorption spectra}

As discussed in section 2.4, the induced absorption spectrum is very broad and potentially complex. A common way to perform the analysis of complex absorption bands consists in using a linear combination of bands with Gaussian profiles in wavenumber (or energy) space [20,21]. Using this technique, it is possible to model the experimental induced absorption spectrum $\left(A_{\text {exp }}(\sigma)\right)$, where sigma is the wavenumber, by a theoretical spectrum $\left(A_{t h}(\sigma)\right)$ equal to:

$$
A_{\mathrm{th}}(\sigma)=\sum_{i=1}^{4} G_{i}(\sigma)=\sum_{i=1}^{4} G_{i}^{0} \exp \left\{-\frac{\left(\sigma-\sigma_{i}^{0}\right)^{2}}{2 \Delta \sigma_{i}^{2}}\right\}
$$

where $G_{i}(\sigma)$ is the Gaussian function, $G_{i}^{0}$, its amplitude, $\sigma_{i}^{0}$, the position of its maximum and $\Delta \sigma_{i}$ its half width at $1 / \mathrm{e}^{2}$. Fitting is performed by minimizing the deviation of the model to the experimental curve. To achieve this, a figure of merit, defined as the sum of the quadratic errors between model and experimental data for each wavenumber, is calculated for each set of parameters and an optimal set of parameters are determined by minimization of this figure of merit:

$$
\left[G_{i}^{0}, \sigma_{i}^{0}, \Delta \sigma_{i}\right]=\min _{G_{i}^{0}, \sigma_{i}^{0}, \Delta \sigma_{i}}\left\{\int_{\sigma_{\min }}^{\sigma_{\max }}\left[A_{\text {exp }}(\sigma)-A_{\mathrm{th}}(\sigma)\right]^{2} d \sigma\right\}
$$

Position and width of each Gaussian function is fixed and is thus the same for each spectrum that is modeled. The number of Gaussian functions is determined as the lowest number that allows fitting of spectra with precision better or equal to the precision of the measurement, i.e. within a few percent. It was found that for induced absorption spectrum in PTR glass, four Gaussian bands are required to perform a fit with RMS $<5 \%$ for all the experimental data obtained in short 
wavelength range $(\lambda<550 \mathrm{~nm}$ but larger than $335 \mathrm{~nm})$ for different dosages and conditions of thermal development (e.g. Fig. 2 showing the induced absorption spectrum of a PTR glass exposed with $4 \mathrm{~J} / \mathrm{cm}^{2}$ and thermally developed for 1 hour @ $515^{\circ} \mathrm{C}$ ). Parameters of these bands are summarized in the Table 1. However, it was found that the usage of Gaussian functions is not enough to model the absorption spectra in long wavelength range $(\lambda>550 \mathrm{~nm})$. To provide a reasonably small RMS, it was necessary to introduce a new function to properly account for the slow absorption decrease in the long wavelength part of the induced absorption spectra.

\subsubsection{Urbach tail in long wavelengths range of induced absorption spectrum}

It was shown for silver halide crystals that the long wavelength shoulders of exciton absorption bands are described by exponential functions and not by Gaussian ones [22]. Later this so called Urbach rule was found for extrinsic [23], intrinsic [24] and induced [25] absorption spectra in silicate glasses. To overcome the problem of fitting the long wavelength tail of induced absorption spectrum in PTR glass, which can be associated with silver and bromine containing particles, the Urbach rule was applied [22]. Based on this model, the long wavelengths tail of the $\mathrm{G}_{1}$ and $\mathrm{G}_{2}$ Gaussian functions can be replaced with an exponential function defined as:

$$
E_{\mathrm{i}}(\sigma)=E_{i}^{1} \exp \left(\alpha_{i} \frac{\sigma}{\sigma_{i}^{1}}\right)
$$

Where $E_{i}{ }^{l}$ and $\alpha_{i}$ are two constants and ${\sigma_{i}}^{l}$ is the wavenumber of stitching between the Gaussian and the exponential functions. Introducing exponential tails for both long wavelength Gaussian bands $G_{1}$ and $G_{2}$, associated with silver halide particles, allows fitting the induced absorption spectrum in PTR glass with RMS $<5 \%$. The parameters used for each exponential band are shown in Table 2. The best fitting was found for the same slopes of exponential tails $\left(\alpha_{i} / \sigma_{i}{ }^{l}\right.$ ratio) 
for both absorption bands. Figure 4 shows how these two bands allow a good fit between model and data over a wide range of wavelength/wavenumber (from $350 \mathrm{~nm}\left(30000 \mathrm{~cm}^{-1}\right.$ ) up to $\left.1500 \mathrm{~nm}\left(7000 \mathrm{~cm}^{-1}\right)\right)$.

\subsubsection{Nucleation}

It was demonstrated in Ref. [10], that when PTR glass is aged at $480^{\circ} \mathrm{C}$, silver containing nuclei appear while little to no $\mathrm{NaF}$ crystal growth can be observed. It was demonstrated that the induced absorption appears concurrently with silver containing nuclei and its spectral shape evolves during heat treatment. This induced absorption was simply associated with silver bromide particles [10]. Using the model presented in the two previous sections, the evolution of the induced absorption spectrum was revisited. PTR glasses were UV-exposed with a dosage of $0.9 \mathrm{~J} / \mathrm{cm}^{2}$ and then nucleated for durations from 5 minutes to 245 minutes at $480^{\circ} \mathrm{C}$. Absorption spectra were measured after each thermal treatment and induced absorption spectra were retrieved from experimental data (Fig. 5). One can see that induced absorption arises during first few minutes and its intensity is weakly dependent on aging time. However, the spectral shape of induced absorption evolves during the heat treatment process. The maximum of absorption spectrum shifts to longer wavelengths from 410 to $485 \mathrm{~nm}$, when aging time increases from 5 to $180 \mathrm{~min}$ and then shifts back to $465 \mathrm{~nm}$ when nucleation duration is further increased. Each induced absorption spectrum was then decomposed using the described earlier sum of four Gaussian and two exponential functions. It was found that the evolution of induced spectrum can be completely described by a combination of the same functions by varying their amplitudes only. The evolution of each band as a function of aging time at $480^{\circ} \mathrm{C}$ is shown in Fig. 6. Since the amplitude of the exponential tails is directly related to the amplitude of their corresponding 
Gaussian bands, only the amplitudes of the Gaussian bands were plotted. Note that the evolution of the components is not monotonic (discussed below).

\subsubsection{Crystallization}

After analyzing the evolution of the induced absorption spectra during the nucleation process, the evolution of the same bands during crystallization at higher temperatures was studied. UVexposed PTR glass samples were thermally developed for different durations of 1,2 and 3 hours at $515^{\circ} \mathrm{C}$. The choice of $515^{\circ} \mathrm{C}$ comes from the fact that growth occurs much more slowly at $480^{\circ} \mathrm{C}$ than at $515^{\circ} \mathrm{C}$ and therefore increasing the development temperature permitted us to speed up the processes. Then, the losses spectra were measured and induced absorption spectra were extracted and fitted using the Gaussian and exponential functions described earlier (Tables 1 and 2). Then dependence of the amplitude of each band on thermal treatment duration is plotted in Fig. 7. Similar to the nucleation process, evolution of different absorption bands is not monotonic and it requires a detailed discussion.

\subsection{Analysis of the induced scattering in PTR glass}

\subsubsection{Rayleigh scattering modeling}

Scattering in PTR glass appears after precipitation of the microcrystalline phase of NaF. Scattering spectra were retrieved from experimental data as was described in Section 2.4. The spectral dependence of scattering $\left(S_{t h}(\sigma)\right)$ was modeled using a single exponential function:

$$
S_{\mathrm{th}}(\sigma)=S_{0}\left(\frac{\sigma}{\sigma_{0}}\right)^{N},
$$

where $\sigma_{0}$ is constant, the scattering coefficient at $\sigma_{0}$ is $S_{0}\left(\mathrm{~cm}^{-1}\right)$ and $N$ is a real number This formula is usually written for wavelengths but we converted it to wavenumbers to have the same 
units as for Gaussian and exponential fitting of absorption spectra. One can see in the insert of Fig. 3 that the scattering spectrum when plotted in logarithmic scales is a line with a slope equal to 4 , i.e. this spectrum can be fitted by an exponential function (Eq. 4) with power $N=4$. Actually, the coefficient $N$ determines the type of scattering in a medium. In thermally developed PTR glass, scattering is known to be due to the NaF nano-sized crystals dispersed in the glass matrix and therefore induced scattering follows Rayleigh scattering [8]. The value of power $N=4$ confirms Rayleigh scattering in PTR glass. The scattering coefficient at a fixed wavelength $S_{0}$ (we used $\sigma_{0}=10000 \mathrm{~cm}^{-1}, \lambda_{0}=1 \mu \mathrm{m}$ ) was then determined by minimization of the figure of merit at constant $N$ coefficient:

$$
S_{0}=\min _{S_{0 i}}\left\{\int_{\sigma_{\min }}^{\sigma_{\max }}\left[L_{\exp }(\sigma)-L_{\mathrm{th}}(\sigma)\right]^{2} d \sigma\right\}
$$

One can see in Fig. 3 that exponential function describes the scattering spectrum with RMS $<5 \%$ in the whole spectral region except the short wavelength region $\left(\lambda \sim 320 \mathrm{~nm}, \sigma \sim 31000 \mathrm{~cm}^{-1}\right)$. Deviations of loss spectra in short wavelength region from the exponential function resulted from contribution of absorption of intrinsic and extrinsic color centers that could not be bleached by visible radiation. Extrinsic color centers include different valence states of cerium (and possibly other dopants) resulted from photoionization and trapping of electrons and holes.

\subsubsection{Influence of dosage and thermal development duration}

In order to study the influence of both the dosage of UV-exposure and the thermal treatment duration, PTR glass samples were UV-exposed with dosages of $0.25,0.5,1,2,4$ and $8 \mathrm{~J} / \mathrm{cm}^{2}$ and then thermally developed for different durations of 1,2 and 3 hours at $515^{\circ} \mathrm{C}$. Then, loss spectra were obtained after bleaching and subtraction of the original absorption (Fig. 3), and which 
represent mainly scattering losses, and analyzed. For each of the 18 samples that were prepared and measured, the scattering spectra were fitted with equation (4). The dependence of scattering on UV-dosage for the different thermal treatment durations at $515^{\circ} \mathrm{C}$ is plotted in Fig. 8. This dependence is dramatically different for different regimes of thermal development. For short duration of thermal development, scattering is the lowest for low dosages, while with increasing the thermal development duration, this tendency is inverted.

\section{Discussion}

The spectra of induced absorption in PTR glass that could be bleached with pulsed visible radiation have a complex shape with a maximum in the blue/green region. For all studied regimes of UV-exposure and thermal development, these spectra can be accurately decomposed using the sum of 4 Gaussian bands (Tab. 1). Two of these bands were shown not to be purely Gaussian but to have long wavelength exponential tails (Tab. 2). This type of decomposition generally assumes that each band can be attributed to one type of particle. Based on the position of each of these bands and some additional hypotheses, each Gaussian band was tentatively associated with a specific type of absorbing center. Regarding the band $\mathrm{G}_{4}$ with a maximum at $\sim 376 \mathrm{~nm}$, we associated this one with the absorption band of intrinsic hole centers created during

UV exposure. This band appears only after UV-exposure and thermal treatment and shows a complex evolution during nucleation and crystallization. A similar absorption band was found in PTR glasses and PTR glass matrix (with no dopants) after $\gamma$-irradiation [26] and after exposure to femtosecond radiation [27]. A similar, very well-known band was also observed in the past in several other multi-component glasses [28] and associated with hole centers created during 
exposure. Thus we can ascribe the $\mathrm{G}_{4}$ band to atomic scale defects in glass matrix, supposedly to hole color centers.

The second band used in the decomposition model $\left(\mathrm{G}_{3}\right)$ is centered at $\sim 412 \mathrm{~nm}$. It is important to recall that the same band (same position and width) was observed in PTR glasses that were not doped with bromine [29], in silver doped glasses and interpreted due to the plasmon resonance of colloidal silver nano-particles formed during the thermal treatment $[16,30]$. The third band $\left(\mathrm{G}_{2}\right)$ with a maximum at $455 \mathrm{~nm}$ also was reported several times in the literature. As it appears only in glasses that were doped with bromine and silver, it is therefore legitimate to associate this band with silver bromide particles [31]. The last band $\left(\mathrm{G}_{1}\right)$ with maximum at $\sim 513 \mathrm{~nm}$, cannot be associated with any well-known species previously reported in the literature. The experiment with bromine-free PTR glass showed that this band appears only if glass is doped with both bromine and silver proving that this band is associated with some type of silver bromide particles. A similar band with a central wavelength between 500 and $600 \mathrm{~nm}$ was observed in PTR-like glass doped with a larger amount of silver [32]. This band was associated with the plasmon resonance of complex nano-particles composed with a $\mathrm{AgBr}$ core surrounded by a silver shell, the position of the resonance depending on the ratio between core and shell radii (silver/silver bromide particles).

Using these 4 bands, the evolution of each of the silver containing particles absorption band during the nucleation process was monitored and analyzed (Fig. 5 and 6). The band $\mathrm{G}_{4}$ of hole centers appears within the first 5 minutes of the thermal treatment and then its amplitude remains almost constant (within the error of the measurement and uncertainty of fitting). Evolution of the 
bands $\mathrm{G}_{1}$ (silver/silver bromide particles), $\mathrm{G}_{2}$ (silver bromide particles) and $\mathrm{G}_{3}$ (silver particles) shows strong interconnection. The first particles to appear are silver ones $\left(\mathrm{G}_{3}\right)$. After 5 minutes at $480^{\circ} \mathrm{C}$, the maximum amplitude of the $\mathrm{G}_{3}$ band is already reached; its amplitude decreases with further aging and the band disappears after aging for 30 minutes. This band could not be detected for aging exceeding 30 minutes, except a sharp peak at 100 minutes at $480^{\circ} \mathrm{C}$. The origin of this sudden reappearance, whether it is an error of the fitting or a due to some structural transformations, is still unknown. The interesting point is that while the amplitude of the band $\mathrm{G}_{3}$ of silver particles decreases, the amplitude of the band $\mathrm{G}_{2}$ of silver bromide particles increases and approaches its maximum when the band of silver $\mathrm{G}_{3}$ disappears. When the band of silver disappears, the amplitude of the band $\mathrm{G}_{1}$ starts to increase and the amplitude of the band of silver bromide particles $G_{2}$ decreases. When the amplitude of the band $G_{1}$ of silver/silver bromide reached its maximum after 100 -minute aging at $480^{\circ} \mathrm{C}$, the amplitude of the $\mathrm{G}_{2}$ band of silver bromide particles reaches its minimum. Finally the amplitude of the $G_{1}$ band decreases and almost disappears. At that time, the amplitude of the $\mathrm{G}_{2}$ band increases again until it stabilizes after aging for about 135 minutes at $480^{\circ} \mathrm{C}$.

This complex interplay between the bands $G_{1}, G_{2}$ and $G_{3}$ reflects a series of complex mechanisms of interconversion of silver containing particles. It appears that colloidal silver particles are first created at the initial stage of the nucleation treatment. Then within 30 minutes at $480^{\circ} \mathrm{C}$, these particles are converted into colloidal silver bromide particles. When all silver bromide colloidal particles have been created, these particles are converted into colloidal silver/silver bromide particles. Maximum absorption, and therefore volume fraction, of these particles is obtained after 100 minutes at $480^{\circ} \mathrm{C}$. This observation can be compared with the 
results reported in Ref. [10] where crystallization kinetics were studied by non-isothermal differential scanning calorimetry. In that paper, it was demonstrated that the crystallization peak of UV-exposed PTR glass started to shift to lower temperatures only after 30 minutes aging at $480^{\circ} \mathrm{C}$. This phenomenon was explained in [10] by creation of nuclei or a catalyzer responsible for the enhancement of crystallization in UV-exposed area of PTR glasses. This correlation between appearance of nucleation centers and an absorption band assigned to silver/silver bromide particles, allows for speculation that silver/silver bromide particles can be associated with those nucleation centers. For thermal treatments exceeding 100 minutes at $480^{\circ} \mathrm{C}$, the amount of silver/silver bromide particles decreases and the $\mathrm{G}_{2}$ band of silver bromide increases again as if silver/silver bromide particles were converted back to silver bromide particles. Finally, the structure of the absorption spectrum of silver containing particles tends to stabilize after 135 minutes at $480^{\circ} \mathrm{C}$. Using this decomposition, some of the very complex mechanisms of heterogeneous nucleation in UV-exposed PTR glass could be revealed. However, as it was reported in Refs $[33,34]$, the band of silver/silver bromide particles exists only at temperatures below $400^{\circ} \mathrm{C}$ and disappears at high temperature. This could be associated with the fact that, at these high temperatures, those particles are expected to melt [16]. This additional observation shows that the role of silver/silver containing particles in the nucleation of UV-exposed PTR glass is even more complex than that in the model described above. However, further investigations are still required to come to a comprehensive description of these processes.

The evolution of the silver containing particles absorption band was also studied during the crystalline phase growth process by aging at $515^{\circ} \mathrm{C}$ (Fig. 7). Each of the induced absorption spectra were fitted with the same Gaussian and Gaussian/exponential bands presented in Tables 
1 and 2 by optimizing their amplitudes only. Good correspondence of modeled and experimental spectra suggests that the developed model is valid at any moment of the thermal development process while the glass is still transparent. One can see that the magnitude of each band tends to change with time. The first observation is that the $\mathrm{G}_{3}$ band of silver particles is not detectable after high temperature $\left(525^{\circ} \mathrm{C}\right)$ treatment. The justification that the small magnitude $\mathrm{G}_{3}$ band that appears after 2 hours of aging (Fig. 7) is a reality but not an artifact of fitting requires some additional study. However, it is possible to suppose that the silver particles are generated early on during the high temperature treatment and are converted to silver bromide particles before they could be detected. The main absorption band of silver bromide particles $\left(\mathrm{G}_{2}\right)$ increases in amplitude with aging and comes to saturation. The long wavelength band $G_{1}$ shows a nonmonotonic behavior at long aging times. Detailed analysis of the absorption spectra after long aging times at high temperature requires some additional effort. First, the longer the thermal development, the higher the scattering (See Fig. 8) that masks induced absorption, especially in the short wavelength region. This effect deteriorates the precision of absorption spectra extraction from the experimental loss spectra. The second possible effect could be connected with the fact that these bands after high temperature treatment might correspond to plasmon but not atomic transitions. Therefore, their width and positions of the bands could depend on the size and chemical structure of each species. It should be repeated that within the precision of the measurements, it was possible to fit all spectra with constant parameters of the bands with the exception of their amplitude. However, more precise measurements might reveal additional details about the evolution of the silver containing particles and their absorption bands. 
The last step of this study was the study of the evolution of scattering losses during the thermal treatment of PTR glass. The main supposition is that scattering comes solely from NaF crystals, with refractive index of 1.32 dispersed in the glass matrix having refractive index of 1.5 [7,8]. It was observed that after thermal treatment at $480^{\circ} \mathrm{C}$, for durations from 0 to 240 minutes, little to no scattering can be detected in the samples. This means that the growth rate of $\mathrm{NaF}$ is very slow at these temperatures and that only an undetectable crystal volume fraction was produced after such thermal treatment. The absence of $\mathrm{NaF}$ crystals after aging at $480^{\circ} \mathrm{C}$ was confirmed by XRD measurements. This result allows for a conclusion that low temperature heat treatment of PTR glass at $480^{\circ} \mathrm{C}$ controls the nucleation process while no crystallization occurs within a few hours of aging. The development at temperature of $515^{\circ} \mathrm{C}$ results in the appearance of scattering which depends on the dosage of UV-exposure and the thermal treatment duration (Fig. 8) as the $\mathrm{NaF}$ crystals grow.

We now analyze the evolution of scattering during the high temperature development at $515^{\circ} \mathrm{C}$ that results in growth of nano-crystals of $\mathrm{NaF}$. For small spherical particles $(\mathrm{r}<<\lambda)$, scattering can be modeled by Rayleigh scattering and therefore can be expressed with the following approximate formula [35]:

$$
S\left(N_{p}, r\right) \propto N_{p} r^{6}
$$

where $N_{p}$ is the volume fraction of crystalline phase, $\mathrm{r}$ is the radius of crystals. Using this formula, the dependence of scattering on dosage of UV-exposure for different thermal treatment duration at $515^{\circ} \mathrm{C}$ can be analyzed. According to Fig. 8, after aging for 1 hour at $515^{\circ} \mathrm{C}$, scattering grows with a dosage increase. This means that for a short period of thermal development, crystals do not have enough time to grow, volume fraction of crystals is far from 
saturation, no depletion of sodium and fluorine occurs, and therefore crystal radius $(r)$ is about the same for any dosage. However, the concentration of nucleation centers and therefore $\mathrm{NaF}$ crystals number density and volume fraction $(N p)$ is increased in the area exposed with higher dosage. According to Eq. 6, an increase of volume fraction causes the increase of scattering at higher dosages.

Comparing to a short development time, aging for 3 hours at $515^{\circ} \mathrm{C}$ results in higher scattering and an opposite dependence of scattering on dosage where scattering decreases with increasing dosage (Fig. 8, curve 3). This effect is associated with the fact that there are two competing effects, i.e. the effects of crystal size and crystal number density that have different amplitudes of contribution. Actually, for longer thermal developments, crystals have time to grow, depletion of sodium and fluorine occurs, the volume fraction of crystalline phase $\left(N_{p}\right)$ approaches saturation and has a weak dependence on dosage. Therefore regions where the concentration of nucleation centers is low (low dosage area) enable the growth of a small number of large crystals, while regions where nucleation centers concentration is high (high dosage area) have a great number of small crystals. Due to the $6^{\text {th }}$ power dependence of the scattering versus crystal radius, scattering decreases with dosage because of decreased size of individual crystals. Thermal development for 2 hours at $515^{\circ} \mathrm{C}$ shows almost no dependence of scattering on dosage (Fig. 8, curve 2) which means that these effects compensate for one another.

Often, the concentration of crystals in two-phase systems is estimated by magnitude of scattering resulted from difference on refractive indices in crystalline and vitreous phases. However, effect of crystallite size on intensity of scattering is higher than volume fraction of crystalline phase. 
For example, it is known that induced refractive index in PTR glass is the result of precipitation of nano-sized crystalline phase of $\mathrm{NaF}$ and that the magnitude of the refractive index change is proportional to the magnitude of X-ray diffraction $[7,8]$. While scattering is the result of the precipitation of the same crystals, there is no simple correlation between intensities of scattering and photo-induced refractive index change (difference of the average refractive indices in UVexposed and unexposed regions. Depending on the required refractive index change, the use of low or high dosage in combination with different schedules of thermal development allows optimizing the losses of holographic optical elements.

\section{Conclusions}

The experimental study and modeling of induced absorption and scattering spectra in photothermo-refractive glasses exposed to UV radiation and aged at elevated temperature have shown that, under all studied conditions of exposure and thermal treatment, induced absorption spectra can be described by a combination of four Gaussian bands (two of them with Urbach exponential tails) and scattering by a single exponential function with power of 4 consistent with classical Rayleigh scattering. These four bands were associated with intrinsic hole centers, and three types of particles consisting of silver, silver bromide and silver bromide with silver shelf (silver/silver bromide). At the initial stage of thermal development at low temperatures, silver particles appear in the beginning then convert to silver bromide containing ones. The longest wavelength band of silver/silver bromide with a maximum at $513 \mathrm{~nm}$ was associated with nuclei or catalyzers of the nucleation process. The second stage of thermal development at higher temperatures results in the gradual growth of absorption of both silver bromide and silver/silver bromide absorption bands. Rayleigh scattering in UV-exposed PTR glasses aged at higher temperatures is caused by 
nano-crystals of NaF. For short development times, scattering increases with dosage because of increased volume fraction of crystalline phase. For long development times, scattering decreases with dosage because of decreased size of individual crystals.

\section{Acknowledgments}

The work has been supported by NASA GSFC contract NNG07-CA04C.

\section{References}

[1] L.B. Glebov, Volume hologram recording in inorganic glasses, Glass Science and Technology 75 C1 (2002) 73-90

[2] L.B. Glebov, "Photochromic and photo-thermo-refractive (PTR) glasses", In: Encyclopedia of Smart Materials, John Wiley \& Sons, New York, 2002.

[3] Oleg M. Efimov, Leonid B. Glebov, Vadim I. Smirnov, High efficiency volume diffractive elements in photo-thermo-refractive glass, Patent No. US 6,673,497 B2, January 6, 2004.

[4] O. Andrusyak, V. Smirnov, G. Venus, V. Rotar, and L. Glebov. Spectral Combining and Coherent Coupling of Lasers by Volume Bragg Gratings. IEEE J. of Selected Topics in Quantum Electronics, 15 (2009) 344-353.

[5] L. B. Glebov. Volume Holographic Elements in a Photo-Thermo-Refractive Glass. Journal of Holography and Speckle, 5 (2008) 1-8.

[6] W. Höland, G. Beall, "Glass-ceramic technology", Publisher American Ceramic Society, Westerville, Ohio, 2002.

[7] T. Cardinal, O.M. Efimov, H.G. Francois-Saint-Cyr, L.B. Glebov, L.N. Glebova, V.I. Smirnov, Journal of Non-Crystalline Solids 325 (2003) 275-281. 
[8] K. Chamma, J. Lumeau, L. Glebova and L. B. Glebov, "Effect of dosage and thermal treatment on photo-thermo-refractive glass crystallization properties", International Congress on Glass (Salvador, Brazil), paper 326, September 2010

[9] L. Glebova, M. Klimov, K. Chamma, L.B. Glebov, "Photo-Structural Transformations in Photo-Thermo-Refractive Glass", International Congress on Glass, Prague July 1-5, 2013 [10] J. Lumeau, A. Sinitskiy, L.N. Glebova, L.B. Glebov and E.D. Zanotto, "Spontaneous and photo-induced crystallization of PTR glass", Phys. Chem. Glasses: Eur. J. Glass Sci. Technol. B, $48(4), 281-284(2007)$

[11]. O.M. Efimov, L.B. Glebov, L.N. Glebova, K.C. Richardson, V.I. Smirnov, Appl. Opt. 38 (1999) 619.

[12] O.M. Efimov, L.B. Glebov, S. Papernov, A.W. Schmid, in: Laser-Induced Damage in Optical Materials, Proc. SPIE 3578 (1999) 554

[13] O.M. Efimov, L.B. Glebov, V.I. Smirnov, Opt. Lett. 23 (2000) 1693

[14] J. Lumeau, A. Sinitskiy, L.N. Glebova, L.B. Glebov and E.D. Zanotto, "Method to assess the homogeneity of photosensitive glasses: application to photo-thermo-refractive glass", Journal of Non-Crystalline Solids 355, 1760-1768 (2009)

[15] O.M. Efimov, L.B. Glebov, H.P. Andre, "Measurement of the induced refractive index in a photothermorefractive glass by a liquid-cell shearing interferometer", Appl. Optics, 41 (2002) 1864-1871.

[16] A. V. Dotsenko, L. B. Glebov and V. A. Tsekhomsky, Physics and chemistry of photochromic glasses, CRC Press (1998) 
[17] M. Anne, J. Lumeau, L. Glebova and L.B. Glebov, "Specific absorption spectra of cerium in multicomponent silicate glasses", Journal of Non Crystalline Solids 356 (44-49), 2337-2343 (2010)

[18] L.B. Glebov and V.I. Smirnov. Interaction of photo-thermo-refractive glass with nanosecond pulses at $532 \mathrm{~nm}$, Laser-Induced Damage in Optical Materials, Proceedings of SPIE $5273,396-401(2004)$

[19] J. Lumeau and L. B. Glebov, "Mechanisms of optical bleaching of silver containing particles in photo-thermo-refractive glass", International Congress on Glass (Salvador, Brazil), paper 320, September 2010

[20] L.B. Glebov, E.N. Boulos, Absorption of iron and water in the Na2O-CaO-MgO-SiO2 glasses II: Selection of intrinsic, ferric, and ferrous spectra in the visible and UV regions, Journal of Non-Crystalline Solids, 242, (1998) 49-62.

[21] P. Pelikán, M. Čeppan, M. Liška, “Applications of numerical methods in molecular spectroscopy, CRC Press, 1994

[22] F. Moser and F. Urbach, "Optical absorption of pure silver halides“, Phys. Rev. 102 (6), $1519-1523(1956)$

[23] F.N. Steele, R.W. Douglas. Phys. Chem. Glasses 5 (1965) 246.

[24] L.B. Glebov, L.B. Popova, M.N. Tolstoi. On the fundamental absorption spectrum in simple silicate glasses. Sov. J. Opt. Technology, 42 (1975) 214-216.

[25] L.B. Glebov. Radiation coloring in the 600-1000 $\mathrm{nm}$ region of high purity sodium calcium silicate glass. Sov. J. Glass Phys. Chem. 9 (1983) 242-244. 
[26] L. Glebov, L. Glebova, E. Rotari, A. Gusarov, and F. Berghmans, "Radiation-induced absorption in a photo-thermo-refractive glass, Photonics for Space Environments X, ed. E.W. Taylor, Proceedings of SPIE 5897 (2005) 58970J-1 - 58970J-6

[27] L. Siiman, J. Lumeau, and L.B. Glebov, "Nonlinear photosensitivity of photo-thermorefractive glass by high intensity laser irradiation", Journal of Non Crystalline Solids, 354, 4070 $-4074(2008)$

[28] J. Schulman, W. Compton, "Color centers in solids", Pergamon Press (1963)

[29] L. Glebova, J. Lumeau, M. Klimov, E.D. Zanotto and L.B. Glebov, "Role of bromine on the thermal and optical properties of photo-thermo-refractive glass", Journal of Non Crystalline Solids, 354, $456-461(2008)$

[30] K. J. Berg, P. Grau, D. Nowak-Wozny, M. Petzold, M. Suszynska, "On the sensitivity of optical and mechanical characteristics of the $\mathrm{Na}+\mathrm{Ag}+$ exchange process in soda-lime silicate glass", Materials Chemistry and Physics 40 (2), 131 - 135 (1995)

[31] Product data sheet on silver bromide - www.photonic.saint-gobain.com

[32] A. P. Nacharov, N. V. Nikonorov, A. I. Sidorov, and V. A. Tsekhomskii, "Influence of Ultraviolet Irradiation and Heat Treatment on the Morphology of Silver Nanoparticles in Photothermorefractive Glasses", Glass Physics and Chemistry, Vol. 34(6), 693 - 699 (2008) [33] J. Lumeau, L. Glebova, G.P. Souza, E.D. Zanotto and L.B. Glebov "Effect of cooling on the optical properties and crystallization of UV-exposed photo-thermo-refractive glass", Journal of Non Crystalline Solids 354, 4730-4736 (2008)

[34] J. Lumeau, L. Glebova and L.B. Glebov, "Evolution of Absorption Spectra in the Process of Nucleation in Photo-Thermo-Refractive Glass", Advanced Materials Research, 39-40, 395 - 398 (2008) 
[35] H. Masuda, K. Higashitani and H. Yoshida, "Powder Technology Handbook", CRC Press; 3 edition, Page 117 (2006)

\section{Tables and figures captions}

Table 1. Parameters of the Gaussian bands used for the fitting the induced absorption spectrum.

Table 2. Parameters of the exponential tails used for the fitting of silver containing particles absorption band.

Figure 1. Spectra of total internal loss in a PTR glass sample. 1 - original absorption spectrum, 2 - after exposure to UV radiation at $325 \mathrm{~nm}$ for $4 \mathrm{~J} / \mathrm{cm}^{2}$ and development for 1 hour at $515^{\circ} \mathrm{C}, 3-$ after additional bleaching by visible radiation at $532 \mathrm{~nm}$.

Figure 2. Absorption induced in PTR glass by UV-exposure and thermal development subsequently bleached by visible radiation (difference between curves 2 and 3 in Fig. 1).

Figure 3. Scattering induced in PTR glass by UV exposure and thermal development (difference between curves 3 and 1 in Fig. 1 - blue circles) and theoretical spectrum of scattering according to Eq. 4 (red curve). Vertical axis is in logarithmic scale and the small inserted graph shows the same data when both axes are displayed on logarithmic scales. 
Figure 4. Decomposition of the induced absorption spectrum in PTR glass using Gaussian and exponential functions. $G_{1}$ and $E_{1}$ are in green, $G_{2}$ and $E_{2}$ in orange, $G_{3}$ in yellow and $G_{4}$ in pink. Experimental data are blue circles while the model prediction is in red.

Figure 5. Induced absorption spectra of PTR glass after UV exposure and nucleation at $480^{\circ} \mathrm{C}$ for different times.

Figure 6. Evolution of the amplitudes of the Gaussian components of the induced absorption spectrum in the process of PTR glass nucleation at $480^{\circ} \mathrm{C}$. Error bars are $\pm 0.03 \mathrm{~cm}^{-1}$ and were estimated by fitting the experimental data using different initial conditions.

Figure 7. Evolution of the amplitudes of Gaussian components of the induced absorption spectrum in the process of PTR glass development at $515^{\circ} \mathrm{C}$.

Figure 8. Dependence of scattering $\left(\mathrm{S}_{0}\right)$ in PTR glass at $1000 \mathrm{~nm}$ on UV-dosage for different thermal treatment durations at $515^{\circ} \mathrm{C}$ from 1 to 3 hours with $\mathrm{N}=4$ for all.

\section{Tables and figures}


Table 1.

\begin{tabular}{c|cccc} 
& $\mathrm{G} 4$ & $\mathrm{G} 3$ & $\mathrm{G} 2$ & $\mathrm{G} 1$ \\
\hline$\sigma_{\mathrm{i}}^{0}, \mathrm{~cm}^{-1}$ & 26575 & 24275 & 22000 & 19500 \\
$\Delta \sigma_{\mathrm{i}}, \mathrm{cm}^{-1}$ & 3465 & 2055 & 3200 & 2800 \\
$\lambda_{\mathrm{i}}^{0}, \mathrm{~nm}$ & 376 & 412 & 455 & 513
\end{tabular}


Table 2.

\begin{tabular}{c|cc} 
& $\mathrm{E} 2$ & $\mathrm{E} 1$ \\
\hline$\alpha_{\mathrm{i}}$ & 8 & 7.2 \\
$\sigma_{\mathrm{i}}{ }^{1}, \mathrm{~cm}^{-1}$ & 20000 & 18000 \\
$\alpha_{\mathrm{i}} / \sigma_{\mathrm{i}}{ }^{1}, \mathrm{~cm}$ & $4 . \mathrm{E}-04$ & $4 . \mathrm{E}-04$
\end{tabular}




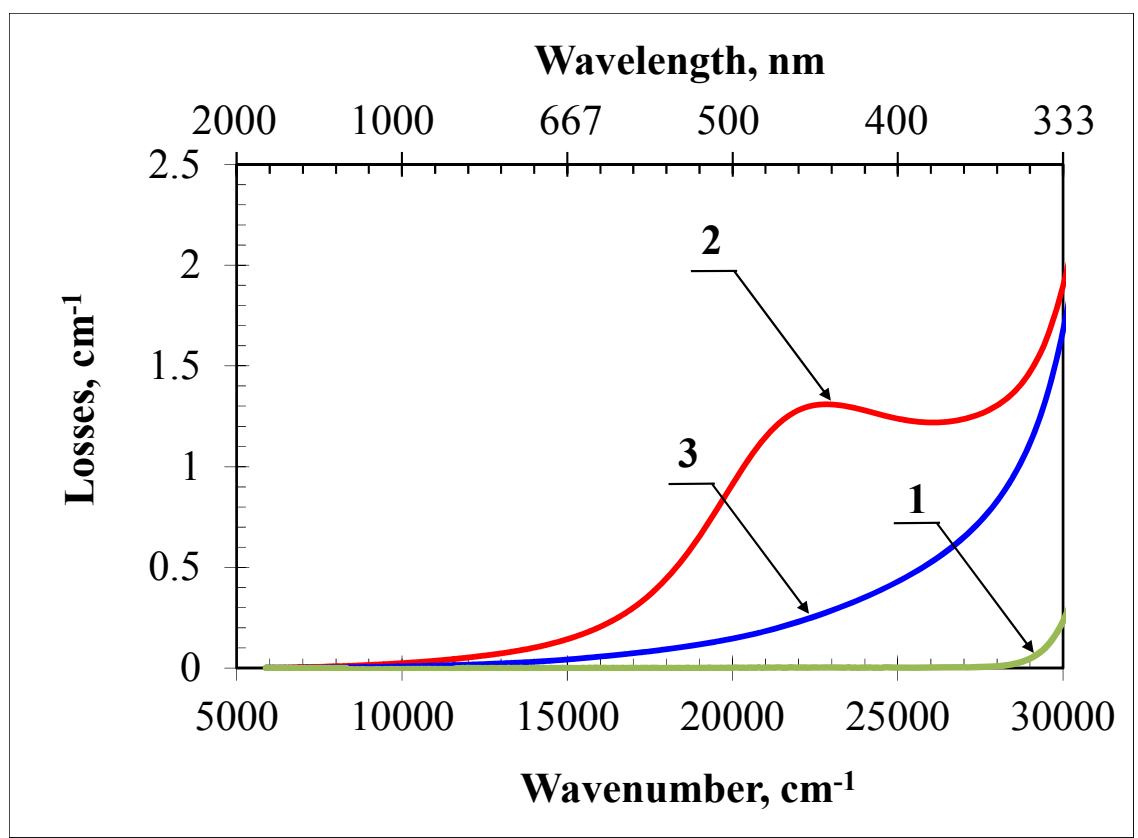

Figure 1. 
Figure 2

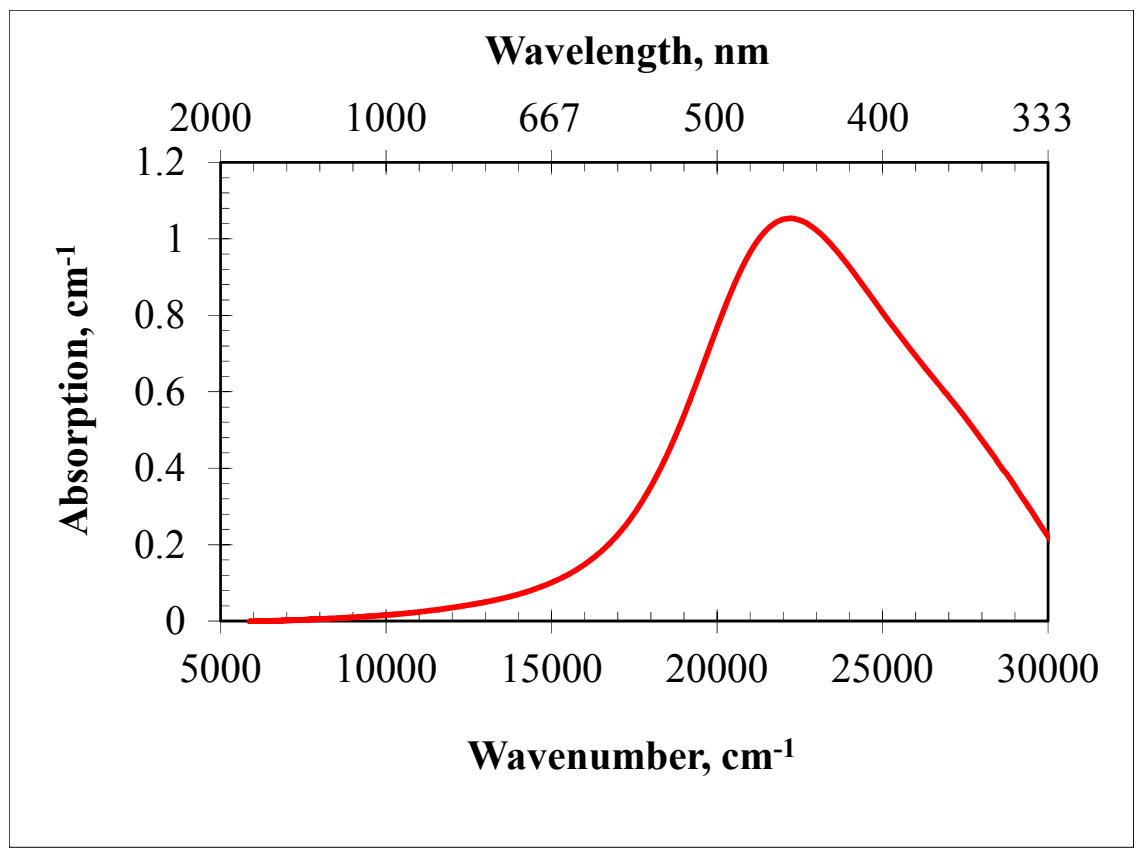

Figure 2. 


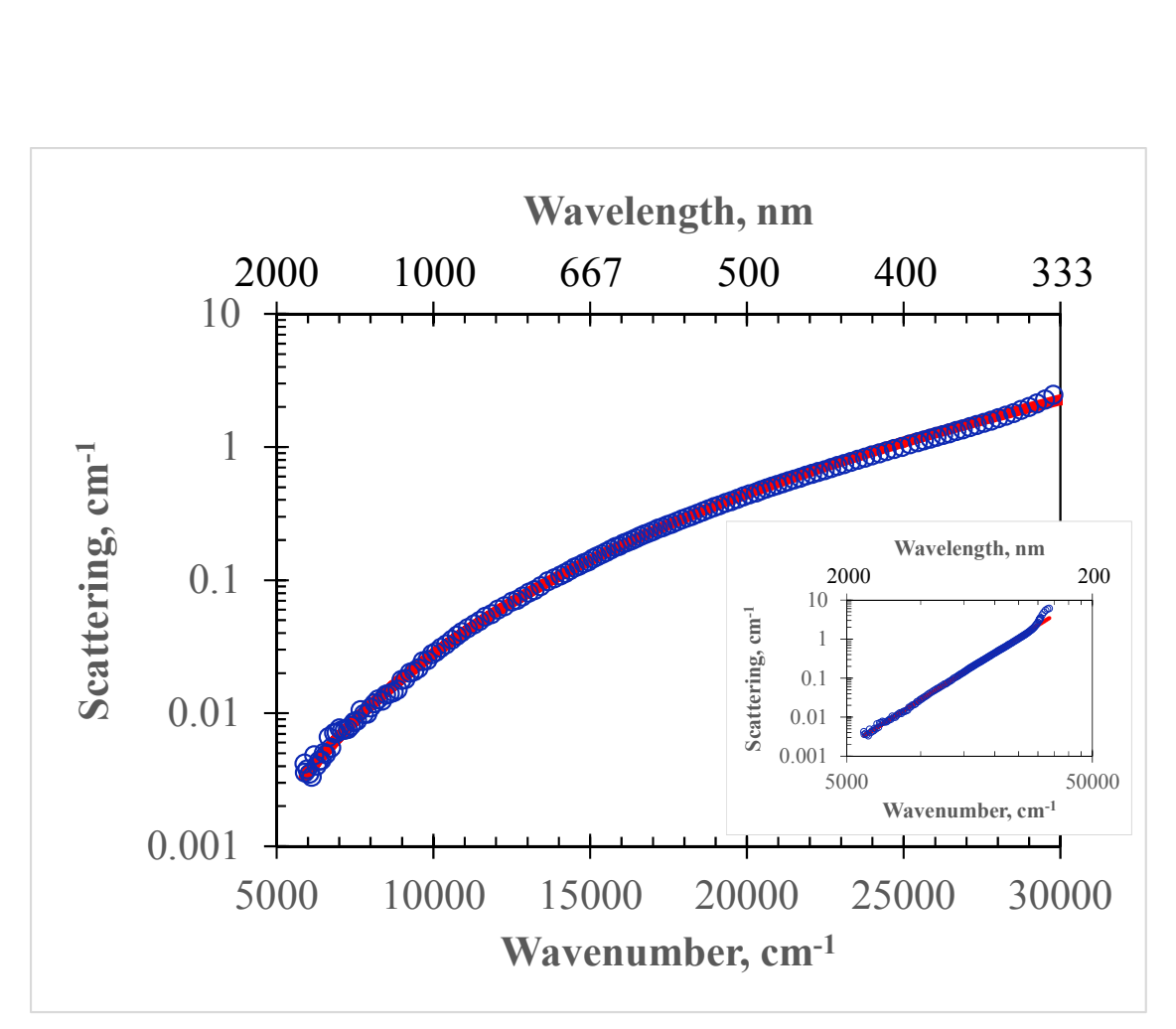

Figure 3

Figure 3

\title{
Figure 3
}

Figure 3

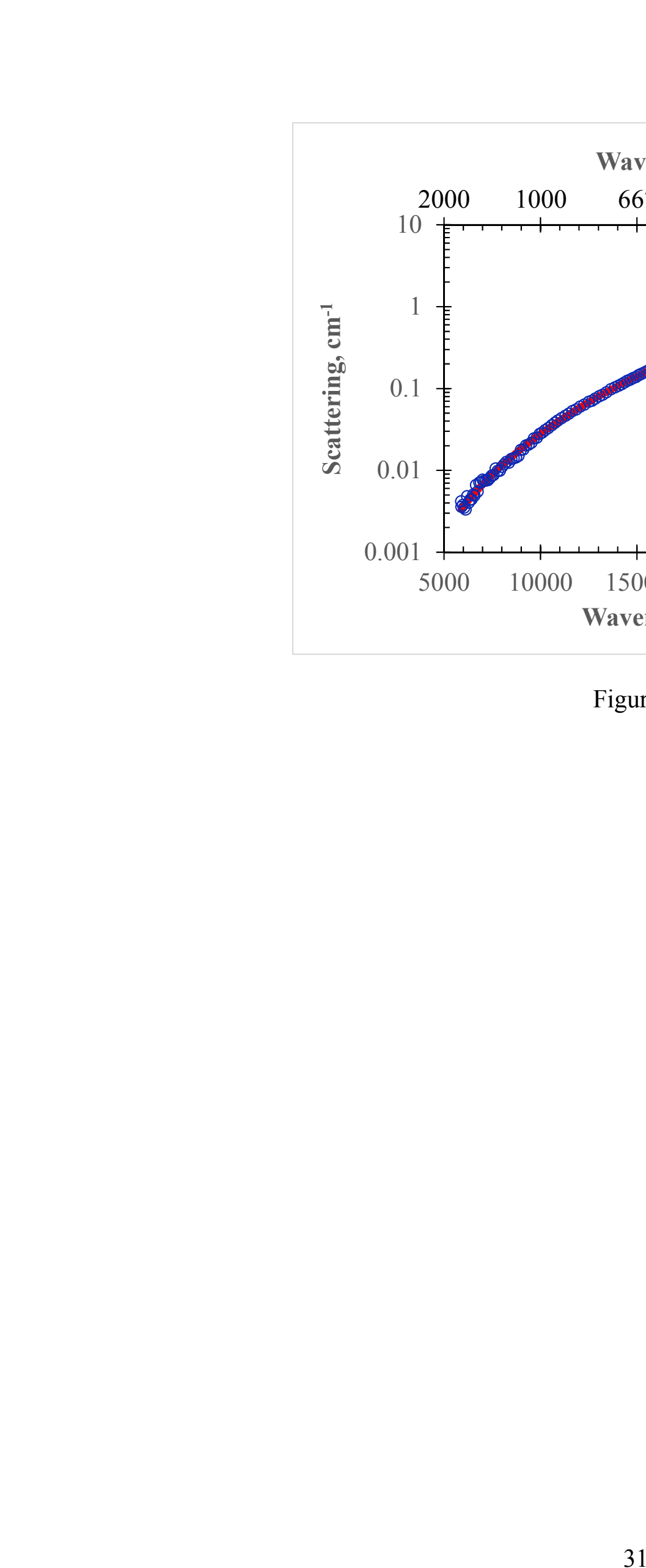

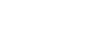

$\sqrt{2}+2$

-

(2)

-

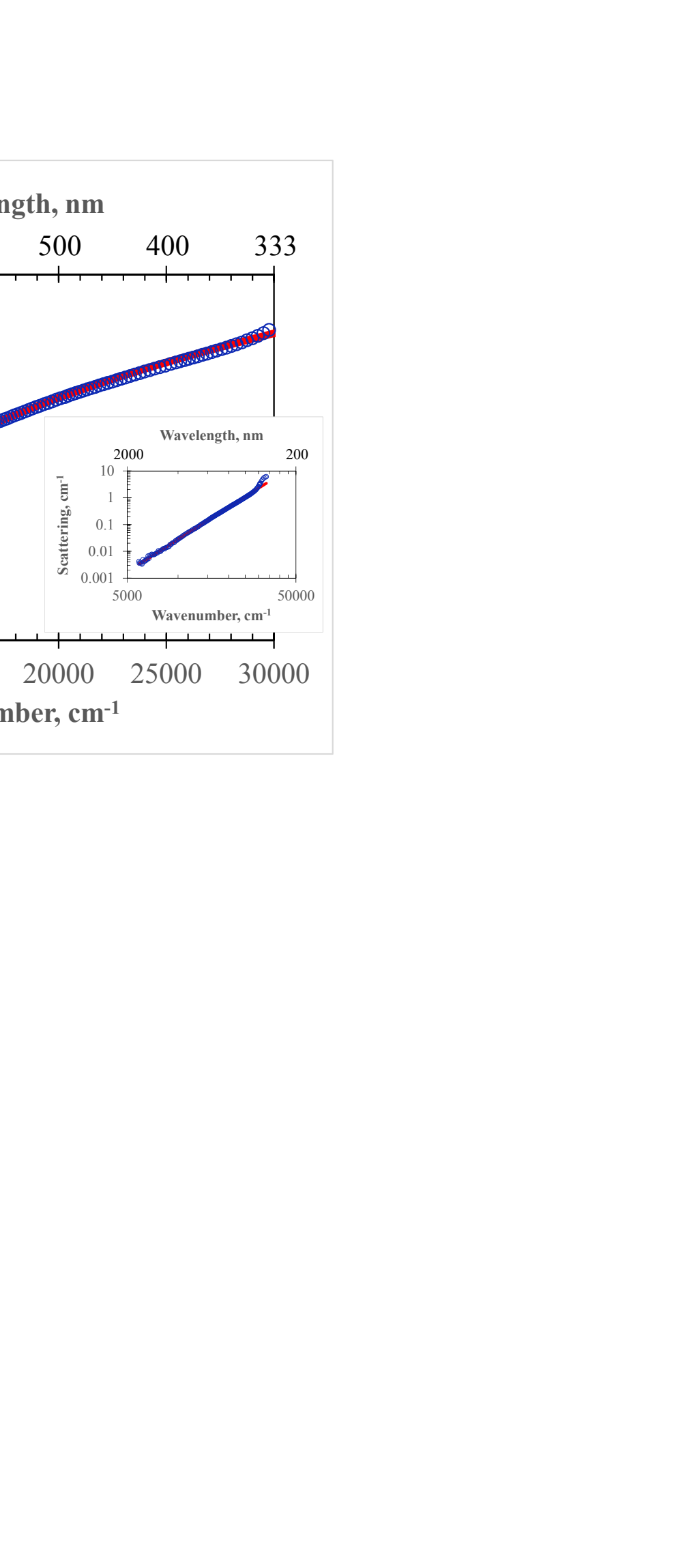

\begin{abstract}
- n
\end{abstract}
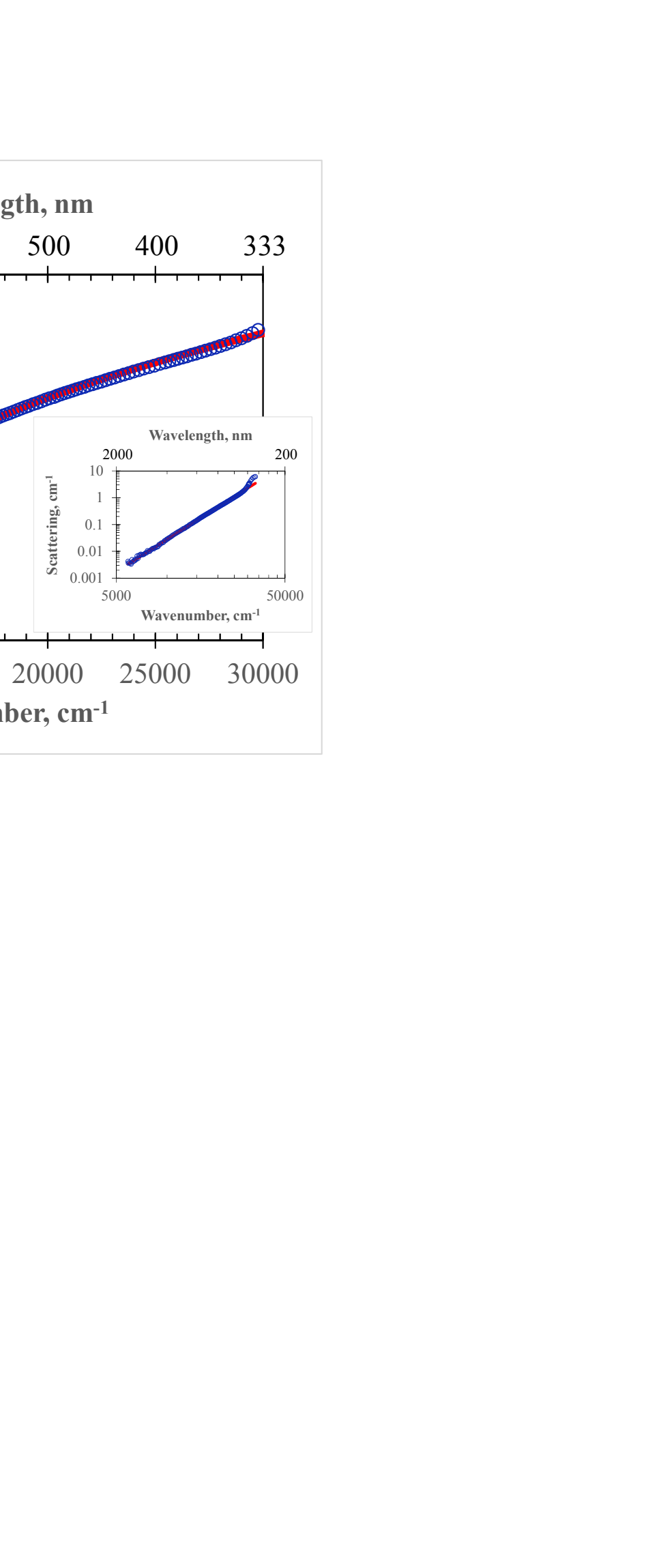

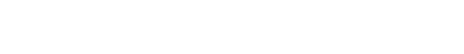

(1)

$\sqrt{2}+2$
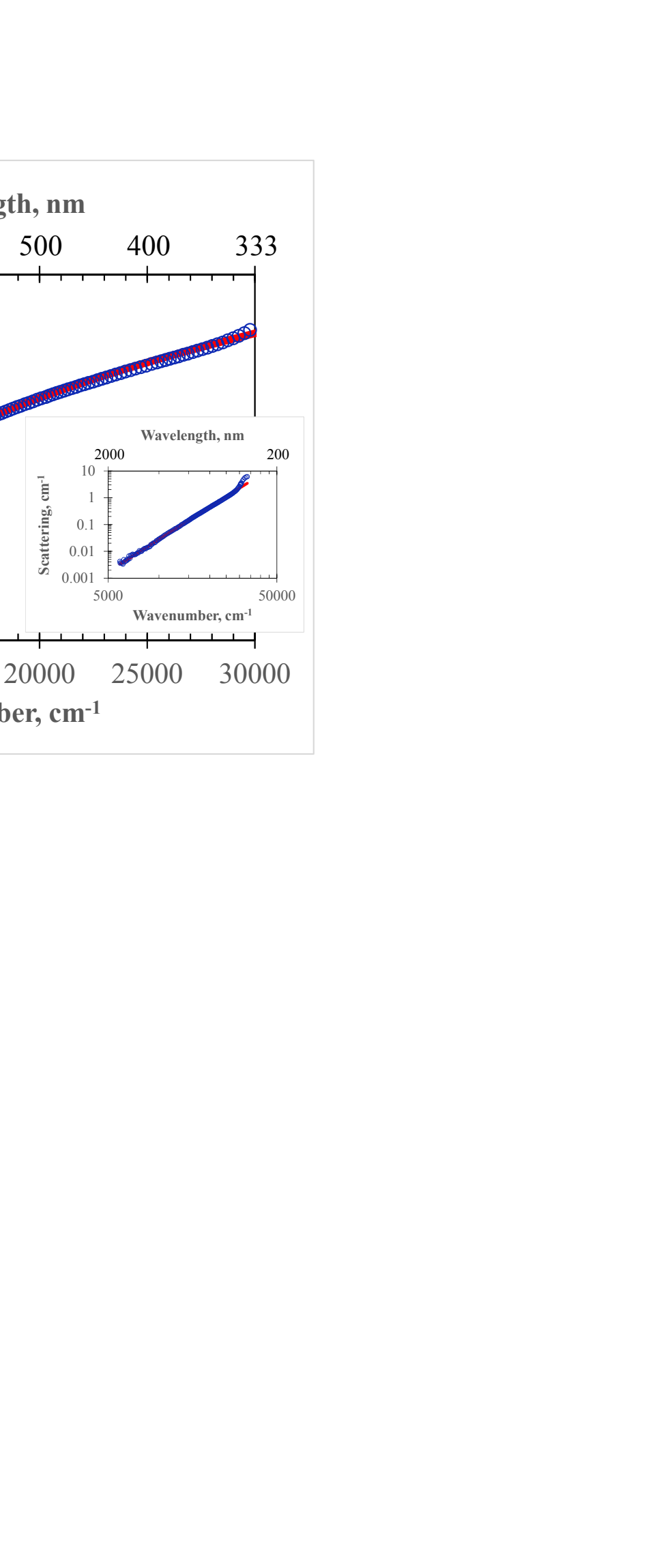

$$
31
$$
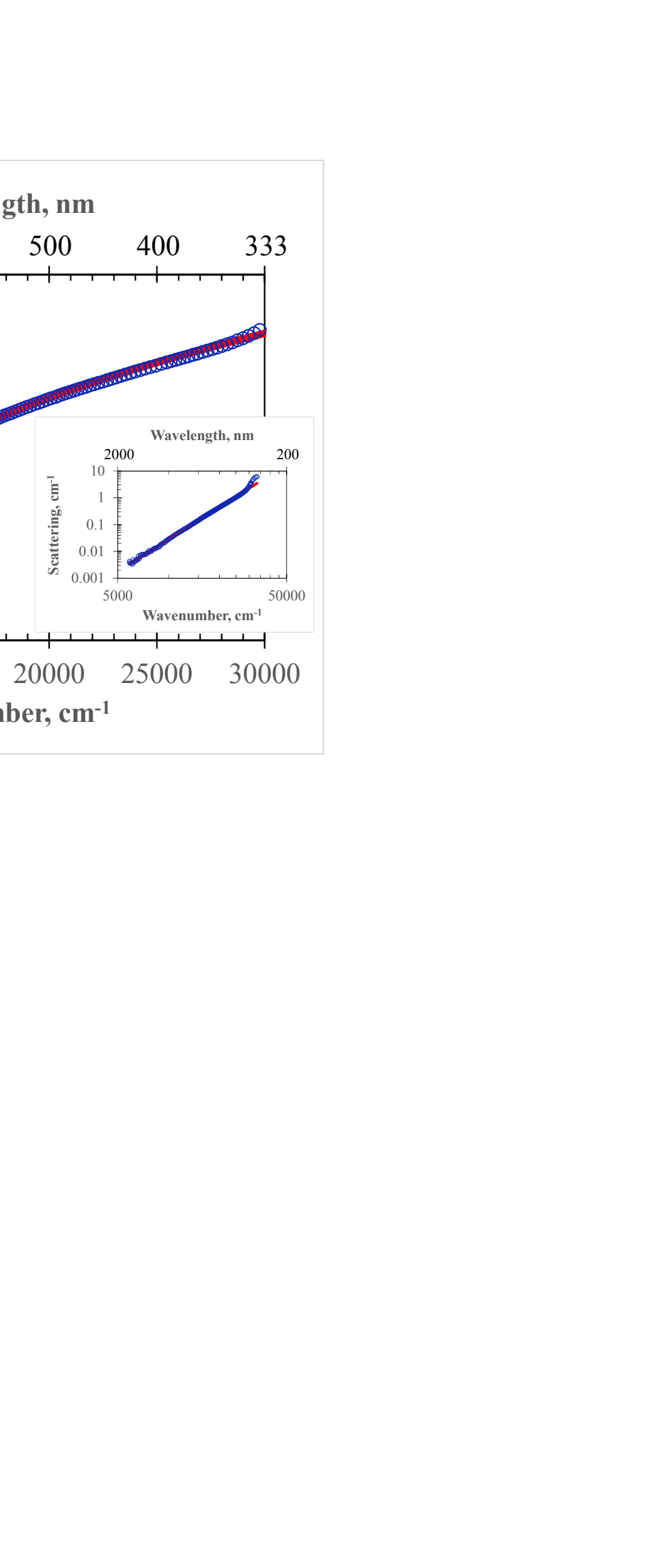


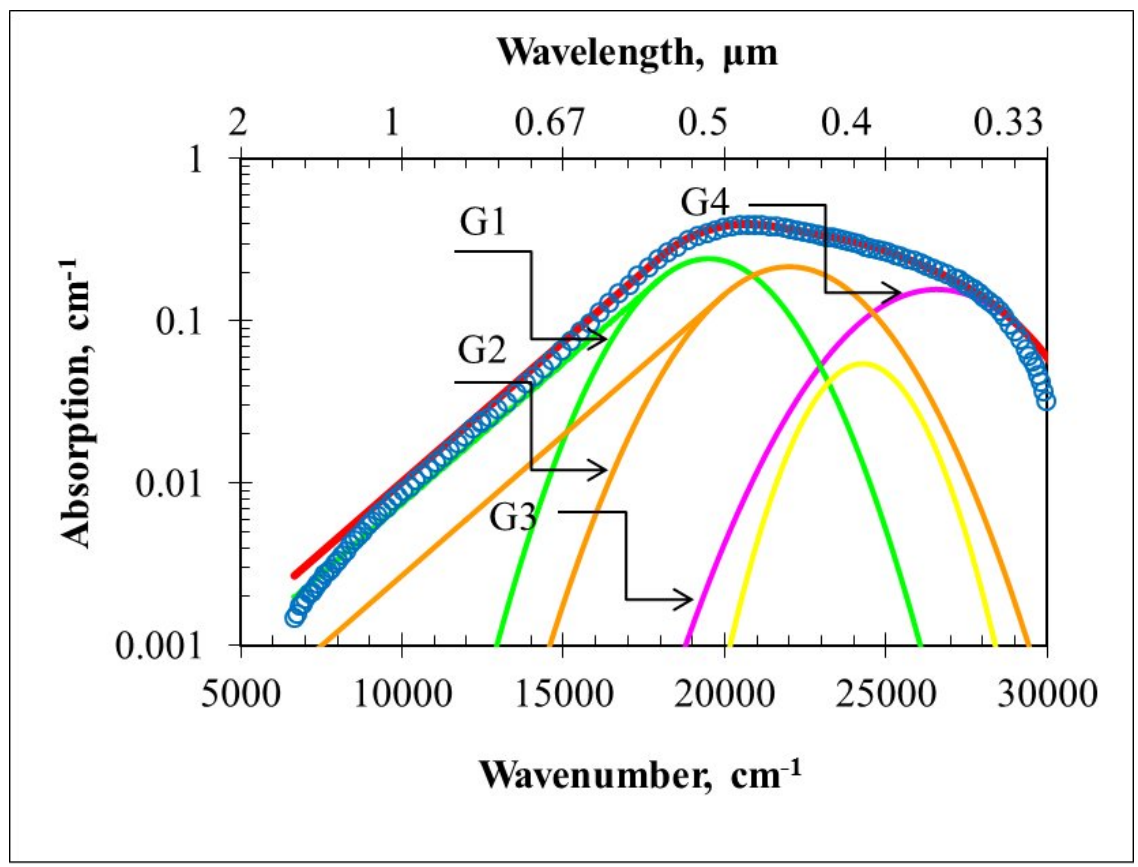

Figure 4. 
Figure 5

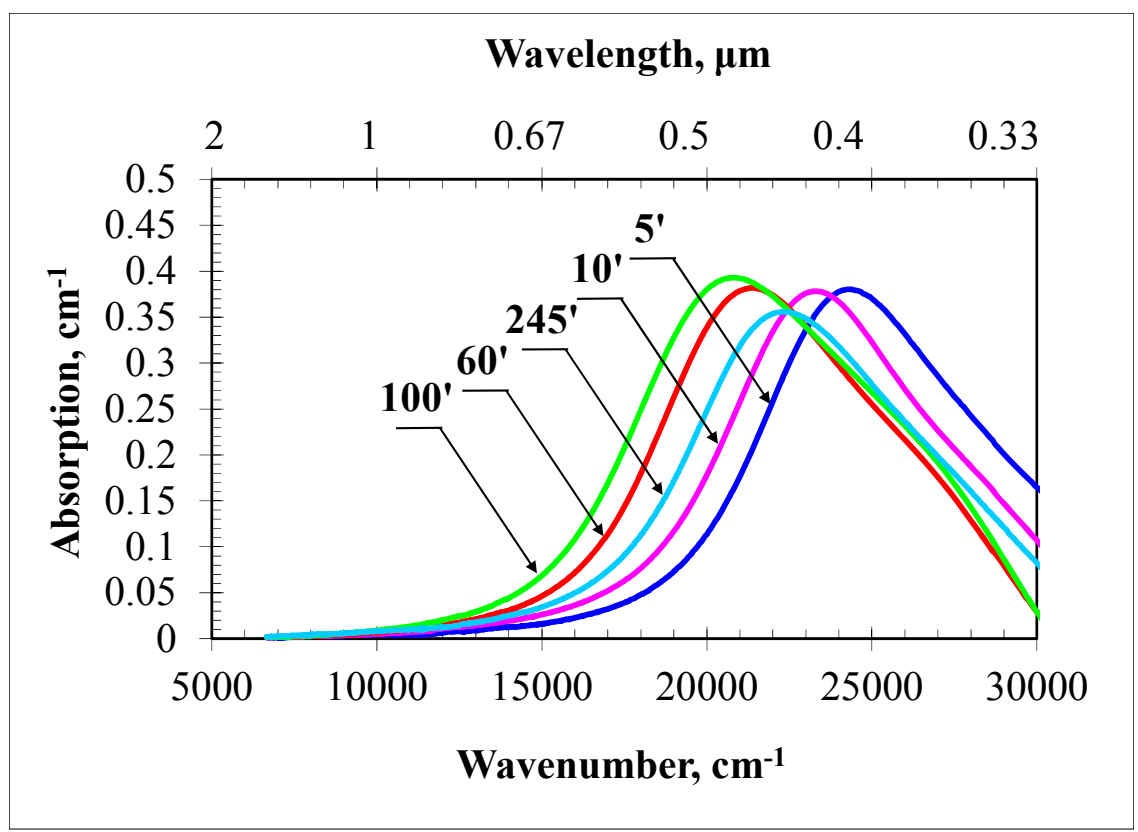

Figure 5. 
Figure 6

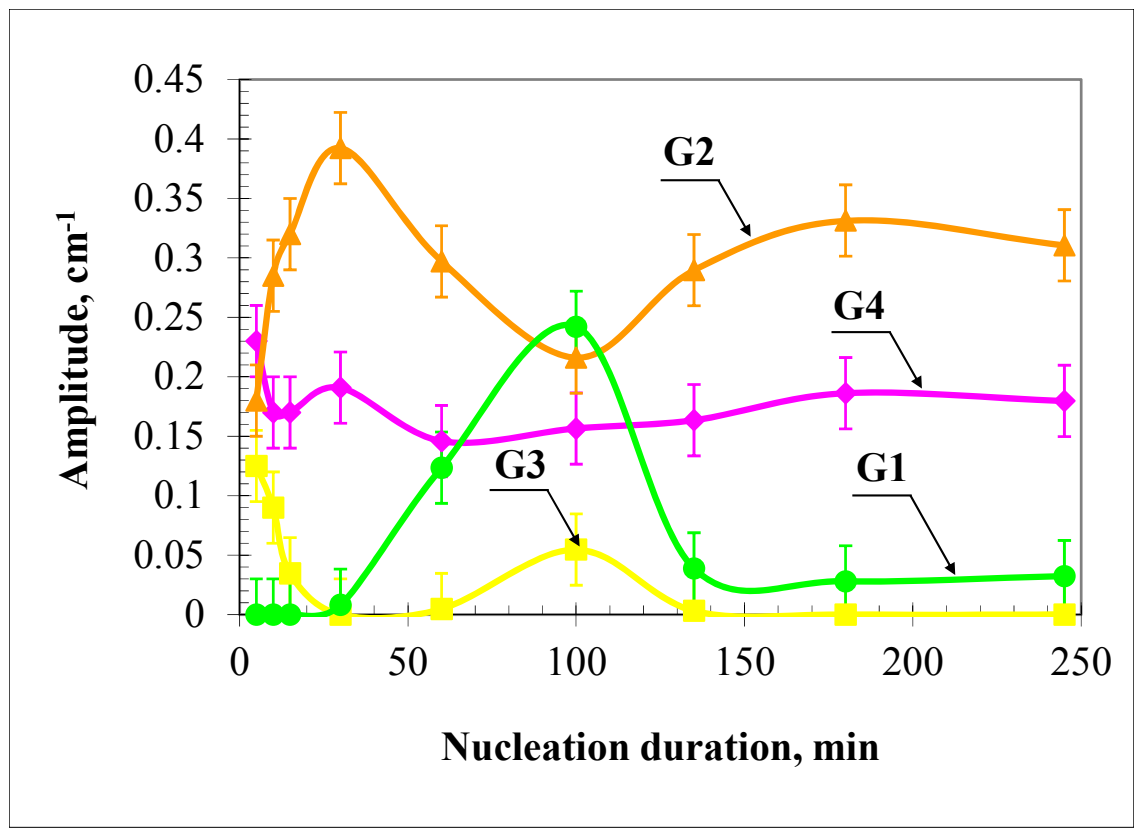

Figure 6. 
Figure 7

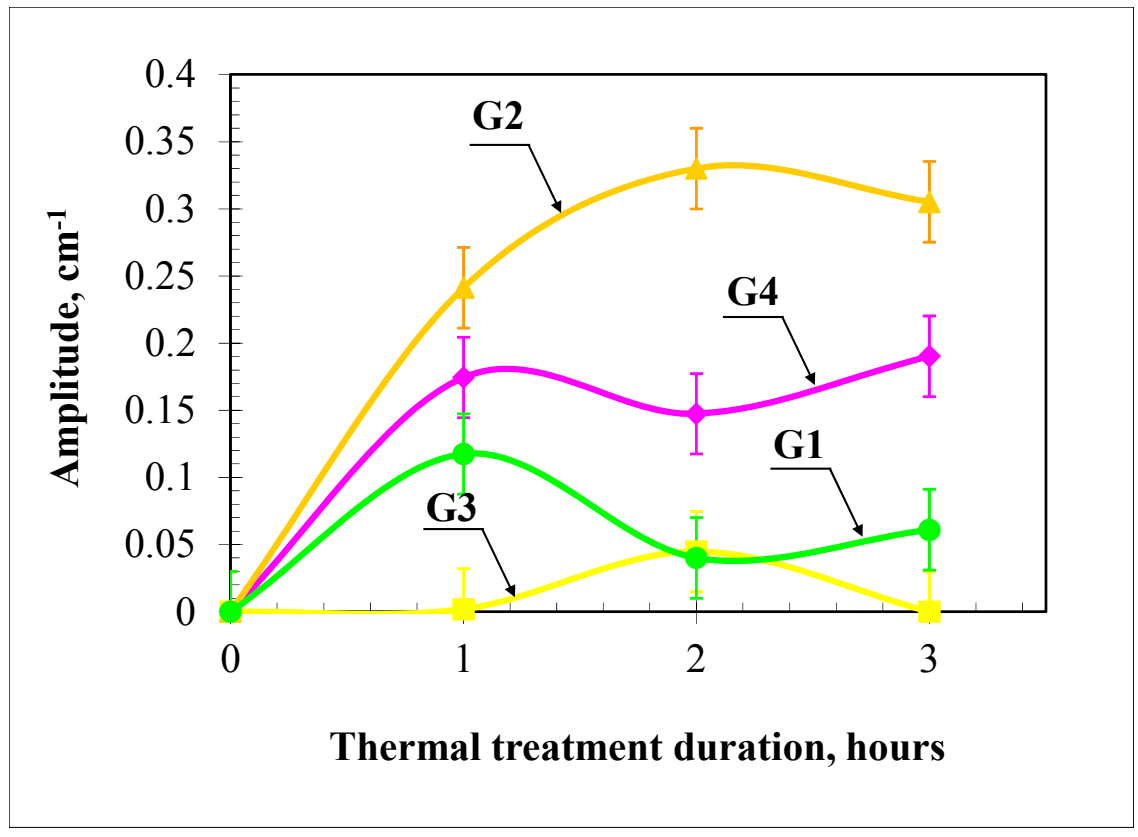

Figure 7 
Figure 8

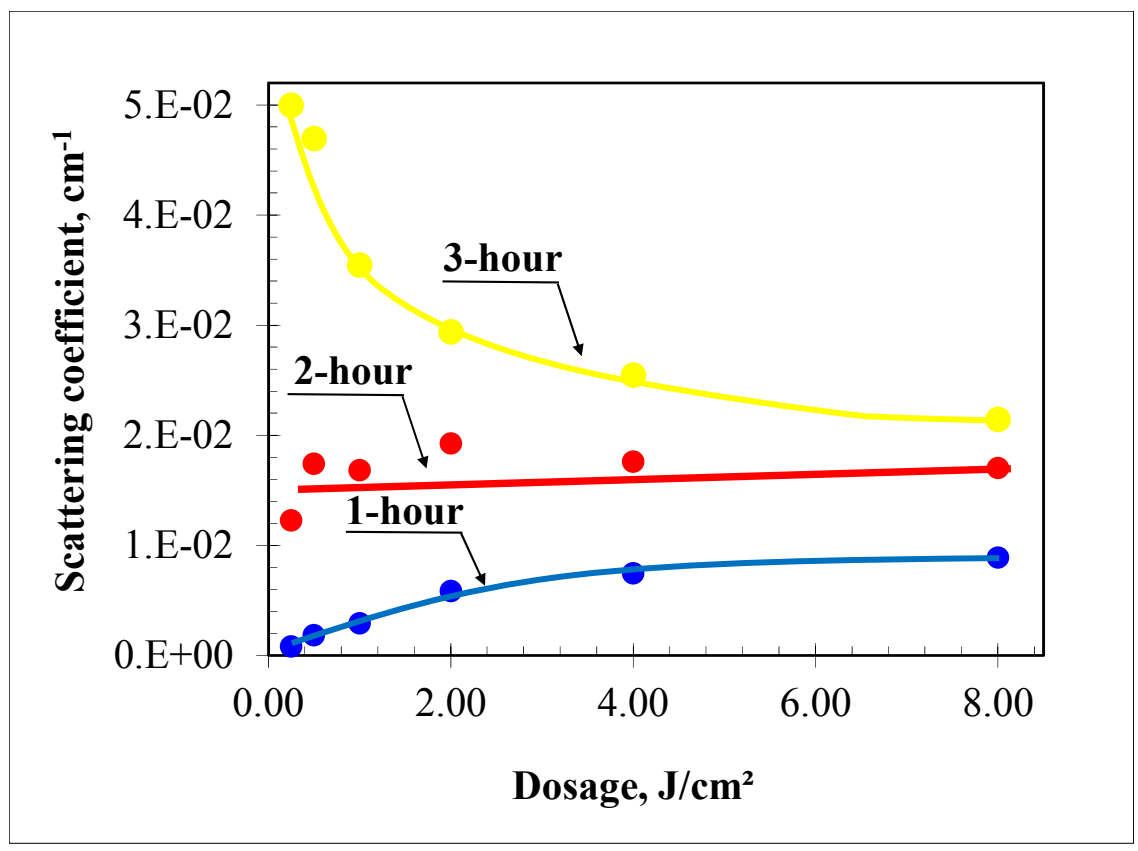

Figure 8. 